\title{
Clinically stable angina pectoris is not necessarily associated with histologically stable atherosclerotic plaques
}

Allard C van der Wal, Anton E Becker, Karel T Koch, Jan J Piek, Peter Teeling, Chris $M$ van der Loos, George K David

\begin{abstract}
Objective-To investigate the extent of plaque inflammation in culprit lesions of patients with chronic stable angina.

Design-Retrospective study.

Setting-Amsterdam reference centre.

Subjects-89 consecutive patients who underwent directional coronary atherectomy, 58 of whom met the following inclusion criteria: chronic stable angina (Canadian Cardiovascular Society classification 1-3 (group 1, $n=28$ )); unstable angina (Braunwald class II (group 2, $\mathbf{n}=$ 18)); unstable angina (Braunwald class III (group 3, $\mathbf{n}=12$ )).
\end{abstract}

Interventions-Directional atherectomy in patients with angina pectoris.

Main outcome measures-Tissue areas of culprit lesions occupied by inflammatory cells and smooth muscle cells related to clinically defined ischaemic syndrome.

Results-Areas (\% of total surface area (mean (SEM)) rich in smooth muscle cells were larger in patients with chronic stable angina (group 1, $51.2(20.9)$ ) than in those with unstable angina (group 2, 42.1 (20.5); group 3, 29.5 (19.4)) (1 $v 2$ and $2 v 3$, NS; $1 v 3, P<0.004)$. Macrophage rich areas were significantly smaller in patients with stable angina (group 1, 21.8 (11.9)) than in those with unstable angina (group 2, $31.5(14 \cdot 6)$; group 3, $46.4(16 \cdot 7)$ ) (1 v 2, $\mathrm{P}<0.02 ; 2 v 3, \mathrm{P}<0.02 ; 1 v 3, \mathrm{P}<$ $0 \cdot 001)$. Mean numbers of $T$ cells per $\mathbf{m m}^{2}$ were as follows: group 1, 17 (9.4); group 2, 25 (15.9); group 3, 41 (30.6) (1 v 2, P 0.04; 2 $v 3$, P 0.07; 1 v 3, P < 0.001). Areas with HLA-DR positive cells showed the same pattern as macrophages and $T$ cells and were smaller in stable $(29.9(12.4))$ than in unstable angina (group 2, 40.4 (17.6); group 3, $52.4(12.0))(1 v 2, P<0.02 ; 2 v 3$, $P<0.05 ; 1$ v 3, P < 0.001).

Conclusion-The inverse relation between the extent of inflammatory activity in plaque tissues of culprit lesions and the clinical stability of the ischaemic syndrome supports the concept that reduction of inflammation favours plaque stabilisation. At the same time, the considerable overlap between groups indicates that patients with clinically stable angina do not all have histologically stable plaques.

(Heart 1996;76:312-316)
Keywords: coronary atherosclerosis; ischaemic coronary syndromes; inflammation; immunohistochemistry

Coronary plaque disruption with subsequent thrombosis is the most common event causing unstable angina or acute myocardial infarction. ${ }^{12}$ Large lipid cores ${ }^{3-5}$ and the distribution of tensile stress in the fibrous $\operatorname{cap}^{367}$ are regarded as important factors contributing to plaque instability before rupture. In addition there is growing evidence that chronic inflammation can also induce vulnerable regions in fibrous cap tissue.

In patients with unstable angina ${ }^{89}$ and acute myocardial infarction, ${ }^{10}$ the coronary artery lesions related to the clinical event have been shown to contain large numbers of macrophages and to a lesser extent $T$ lymphocytes. Participation in a local inflammatory process may trigger macrophages to secrete tissue degrading enzymes (metalloproteinases), which may result in weakening of plaque tissue. ${ }^{112}$ These data are derived almost solely from lesions associated with acute coronary syndromes. Little is known, however, about chronic inflammation in relation to the culprit lesions that underlie clinically stable coronary artery disease, despite the observation that many patients with chronic stable angina develop progressive stenosis of pre-existing coronary artery lesions, which in some is associated with acute coronary events. ${ }^{13}$

Necropsy studies have shown that coronary artery lesions in patients with stable angina show a highly variable architecture, ranging from fibrous to lipid rich. ${ }^{14}$ Recent data, derived from atherectomy specimens have shown that inflammatory cells, and macrophages in particular, are also encountered in culprit lesions from patients with stable angina ${ }^{89}$ Such observations challenge the current concept that chronic inflammation is a marker for plaque destabilisation and, as such, the forerunner of acute coronary events. For this reason we deliberately focused on the presence of chronic inflammation in culprit lesions of patients with chronic ( $>$ two months) stable angina and compared the findings with those in culprit lesions in patients with unstable angina.

\section{Patients and methods}

PATIENTS

Patients with stable and unstable angina were prospectively included in this study. They were enrolled only if the coronary lesion was considered to be suitable for directional coronary 
Table 1 The clinical classification of 58 patients with angina pectoris (AP) and a single culprit lesion, in whom a primary directional coronary atherectomy was performed

\begin{tabular}{|c|c|c|c|}
\hline $\begin{array}{l}\text { Patient } \\
\text { group }\end{array}$ & $\begin{array}{l}\text { Classification of } \\
\text { angina }\end{array}$ & $\begin{array}{l}\text { Clinical } \\
\text { characteristics }\end{array}$ & $\begin{array}{l}\text { Number of } \\
\text { patients }\end{array}$ \\
\hline 1 & $\begin{array}{l}\text { Chronic stable } \\
(\text { CCS class } 1-3)^{\star}\end{array}$ & $\begin{array}{l}\text { Angina of more than } 2 \text { months } \\
\text { duration, without progression } \\
\text { or recent myocardial infarction }\end{array}$ & 28 \\
\hline 2 & $\begin{array}{l}\text { Unstable } \\
\text { (Braunwald's classes } \\
\text { I and II) }{ }^{\star}\end{array}$ & $\begin{array}{l}\text { New onset of severe or } \\
\text { accelerated angina of less than } \\
2 \text { months duration or subactue AP } \\
\text { at rest during the preceding month, } \\
\text { but not within the preceding } 48 \text { hours }\end{array}$ & 18 \\
\hline 3 & $\begin{array}{l}\text { Unstable } \\
\text { (Braunwald's classes III) }\end{array}$ & $\begin{array}{l}\text { Angina at rest, acute within } \\
48 \text { hours and patient dependent on } \\
\text { intravenous treatment with } \\
\text { nitrates and heparin }\end{array}$ & 12 \\
\hline
\end{tabular}

* Based on the classification of the Canadian Cardiovascular Society ${ }^{15}$ and Braunwald's classification of unstable angina. ${ }^{16}$

Table 2 Histopathological evaluation of atherectomy tissues

\begin{tabular}{lllll}
\hline $\begin{array}{l}\text { Patient } \\
\text { group }\end{array}$ & $\begin{array}{l}\text { Fibrous } \\
\text { tissue }\end{array}$ & $\begin{array}{l}\text { Myxoid } \\
\text { tissue }\end{array}$ & Thrombus & Atheroma \\
\hline 1 & $28 / 28$ & $6 / 28$ & $6 / 28$ & $14 / 28$ \\
$(\mathrm{n}=28)$ & $(100)$ & $(21 \cdot 4)$ & $(21 \cdot 4)$ & $(50)$ \\
2 & $18 / 18$ & $8 / 18$ & $11 / 18$ & $13 / 18$ \\
$(\mathrm{n}=18)$ & $(100)$ & $(44 \cdot 4)$ & $(61 \cdot 1)$ & $(72 \cdot 2)$ \\
3 & $12 / 12$ & $4 / 12$ & $10 / 12$ & $11 / 12$ \\
$(\mathrm{n}=12)$ & $(100)$ & $(33 \cdot 3)$ & $(83 \cdot 3)$ & $(91 \cdot 6)$ \\
\hline
\end{tabular}

atherectomy and identified as the "culprit" lesion on the basis of clinical and electrocardiographical findings. Patients were excluded if they had stable angina in the presence of multivessel disease (defined as coronary lesions $>70 \%$ diameter stenosis on visual assessment in more than one major coronary artery) or restenotic coronary lesions. Out of an initial series of 89 consecutive patients, 60 fulfilled these criteria and atherectomy specimens from 58 patients were available for study.

Patients were classified independently by two cardiologists into three groups, according to their admission diagnosis: group 1, chronic stable angina; group 2, unstable angina; group 3 , those with unstable angina who were dependent on intravenous nitrate and heparin. The relevant data are presented in table 1 . The pathologists were blinded to the results of the clinical classification.

\section{HISTOPATHOLOGICAL PROCEDURES}

Atherectomy specimens were snap-frozen in liquid nitrogen and stored at $-80^{\circ} \mathrm{C}$. For histopathological evaluation of the specimens $5 \mu \mathrm{m}$ cryostat sections were stained with haematoxylin and eosin and elastic van Gieson stains and screened for the presence of fibrous cap tissue, lipid rich debris, thrombus, and media. Adjacent $5 \mu \mathrm{m}$ serial sections were stained immunohistochemically with monoclonal antibodies that were reactive with macrophages (anti-CD68: Dakopatts, Glostrup, Denmark), smooth muscle cells (anti $\alpha$-actin; SMA-1: Dakopatts), T lymphocytes (anti-CD3: Becton and Dickinson, Mountain View, CA), and HLA-DR molecules (C3/43: Dakopatts). A three-step indirect peroxidase method was used as previously described. ${ }^{17}$
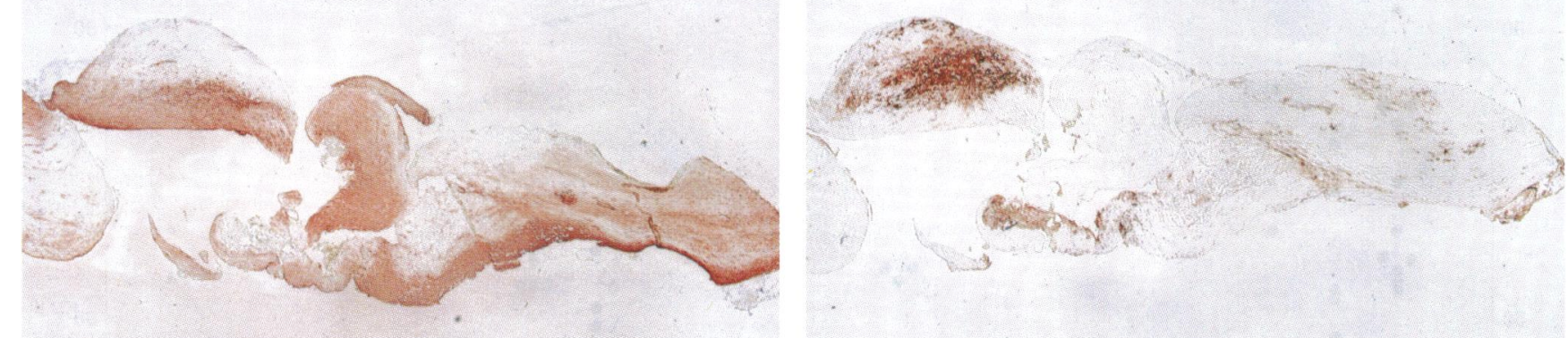

A

B
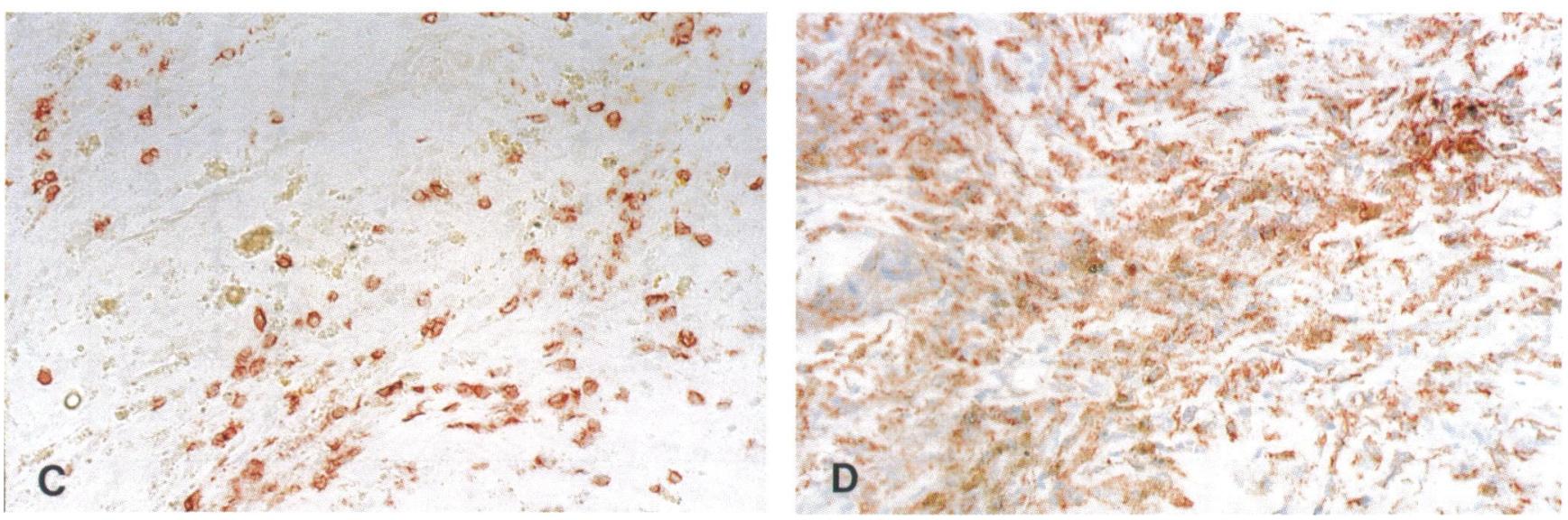

Figure 1 Serial frozen sections of atherectomy tissue obtained from a patient with chronic stable angina, stained for smooth muscle cells (A) and macrophages (B). Note the almost complementary distribution of both cell types. Detail of an infiltrated area showing $T$ lymphocytes in close proximity to ceroid pigment (yellowish material) (C) and abundant $H L A-D R$ expression (D) of macrophages and $T$ cells. Original magnification, $A$ and $B, \times 15$; $C$ and $D, \times 65$. 
IMAGE ANALYSIS

Areas of interest in the immunostained sections were measured by planimetry using TIM image analysis software on a personal computer with a VS-100-AT frame grabber (Data Measuring Systems, Breda, The Netherlands). In the serial sections stained for macrophages, smooth muscle cells, and cells expressing HLA-DR, respectively, areas occupied by immunostained cells were outlined and calculated as a percentage of the total surface area, excluding media. $T$ lymphocytes $\left(\mathrm{CD}^{+}\right)$were counted at $\times 100$ throughout the entire section, and expressed as number of cells per $\mathrm{mm}^{2}$.

\section{STATISTICAL ANALYSIS}

The results of area quantification and $T$ cell counting are expressed as mean values (SEM). The relation and differences between the three patient groups were evaluated by the analysis of variance and a two-tailed Student's $t$-test. $P$ values $<0.05$ were regarded as significant.

\section{Results}

HISTOPATHOLOGICAL ANALYSIS

The results of the histopathological analysis (presence of fibrous cap, thrombus, lipid rich core material, media) are shown in table 2 . In 18 of the 58 specimens areas were identified which consisted of an abundant and loosely arranged myxoid matrix, containing stellate smooth muscle $\left(\mathrm{SMA}-1^{+}\right)$cells with eosinophilic cytoplasm. These areas differed markedly from the usual fibrous tissue (fibrocellular or fibrosclerotic) and were counted separately as "myxoid intimal tissue".

\section{IMMUNOHISTOCHEMICAL ANALYSIS}

All specimens contained inflammatory cells (macrophages and T cells) and smooth muscle cells, although in highly variable proportions. Macrophages $\left(\mathrm{CD}^{+} 8^{+}\right.$) and $\mathrm{T}$ cells $\left(\mathrm{CD}^{+}\right)$ always showed the same tissue distribution within the sections and were frequently found in areas containing ceroid pigment. Smooth muscle cells (SMA-1 ${ }^{+}$) were found either loosely arranged or tightly packed in fibrous cap tissue, in medial fragments, and in organised thrombus. Myxoid intimal tissue-as defined above-contained few macrophages and $T$ cells only. In all three patient groups HLA-DR expression was found on macrophages and on some of the $T$ lymphocytes and smooth muscle cells. A striking observation was the strict zonal distribution of smooth muscle cells and inflammatory cells. Most areas infiltrated with macrophages were largely devoid of smooth muscle cells, whereas most smooth muscle cell areas contained no or few inflammatory cells. This distribution produced almost complementary patterns (see also fig 1 ).

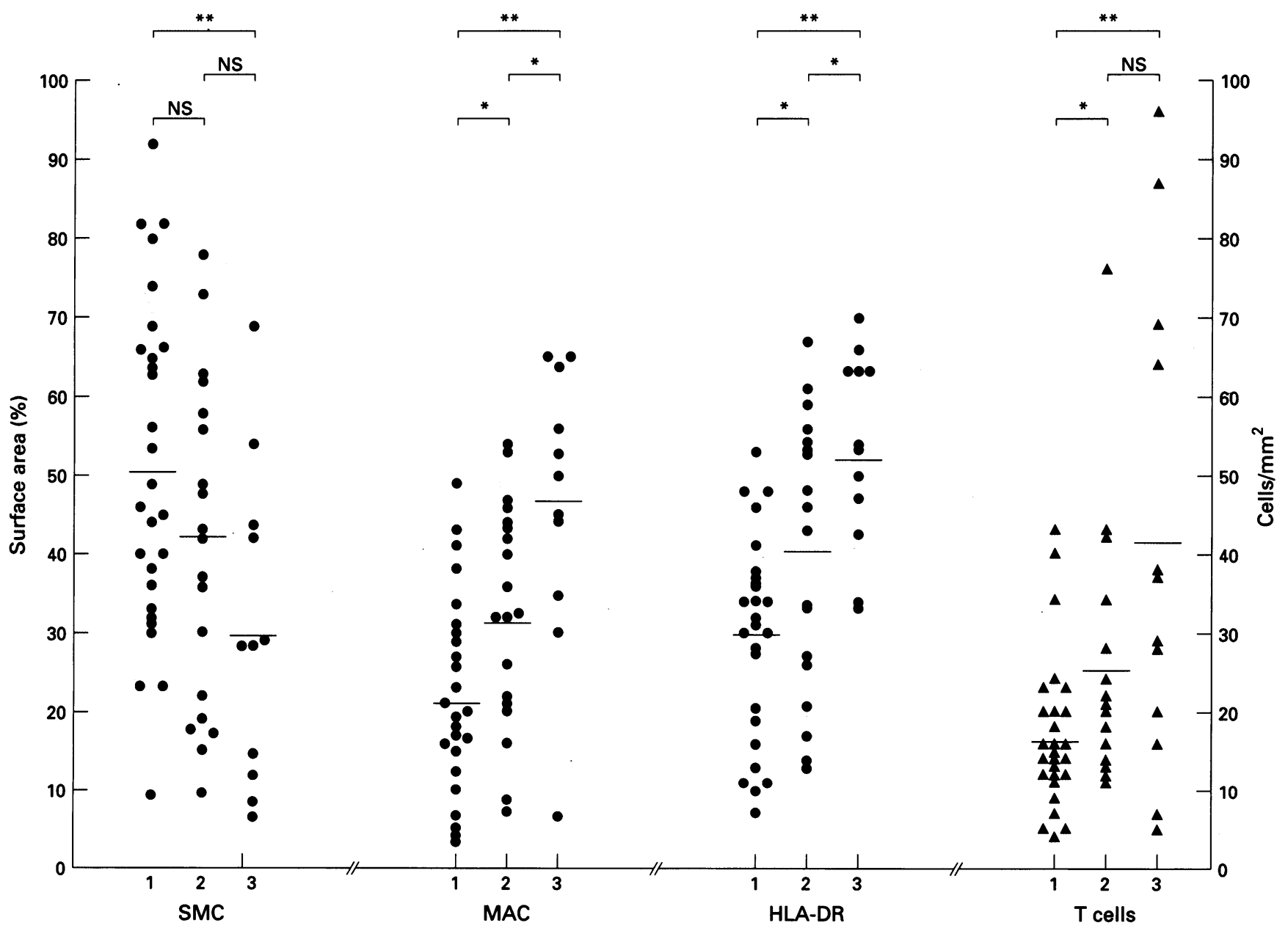

Figure 2 Individual point plots for percentages of tissue areas occupied by smooth muscle cells (SMC), macrophages (MAC), and cells expressing $H L A-D R$ (HLA-DR) and the number of T lymphocytes per $\mathrm{mm}^{2}$ for each atherectomy specimen in the three patient groups. Note the considerable overlap between the three groups. Bars represent mean values. ${ }^{*} P<0.05 ; \star * P<0.005$. 


\section{IMAGE ANALYSIS}

Area quantification of immunostained sections showed that areas rich in smooth muscle cells were larger in patients with chronic stable angina (group 1, 51.2(20.9)) than in those with unstable angina (group 2, 42.1 (20.5; group 3, 29.5 (19.4)) (1 $v 2$ and $2 v 3$, NS; $1 v$ $3, \mathrm{P}<0.004)$. Macrophage rich areas were significantly smaller in patients with stable angina (21.8 (11.9)) than in those with unstable angina (group 2, 31.5 (14.6); group 3, $46.4(16.7))(1 v 2, \mathrm{P}<0.02 ; 2 v 3, \mathrm{P}<0.02$; $1 v 3, \mathrm{P}<0.001)$. Mean numbers of $\mathrm{T}$ cells per $\mathrm{mm}^{2}$ were: group $1,17(9 \cdot 4)$; group 2,25 (15.9), and group 3, $41(30.6)$ (1 v 2, $\mathrm{P}<$ $0.04 ; 2$ v 3, $\mathrm{P}<0.07 ; 1$ v $3, \mathrm{P}<0.001)$. Areas with HLA-DR positive cells followed the same pattern of distribution as the macrophages and $T$ cells and were smaller in stable (29.9 $(12.4)$ ) than in unstable angina (group 2, 40.4 (17.60; group 3, $52.4(12 \cdot 0)$ ) (1 v 2, $\mathrm{P}<0.02$; $2 v 3, \mathrm{P}<0.05 ; 1 v 3, \mathrm{P}<0.001)$. All data are individually point plotted in fig 2 .

The macrophage/smooth muscle cell ratio was calculated for each of the 58 atherectomy samples. Mean values of the ratios per patient group shifted from 0.57 in group 1 , to 0.92 in group 2 , and to $2 \cdot 49$ in group 3 .

\section{Discussion}

Our study, based on atherectomy specimens, shows considerable overlap in chronic inflammation between culprit lesions from patients with chronic stable angina and those obtained from patients with unstable angina (fig 2).

Quantification of inflammatory variables showed a statistically significant increase in macrophages and $T$ lymphocytes with an increase in angina state. Active inflammation was indicated by a similar increase in areas containing HLA-DR positive cells, which relate to macrophages and-to a lesser extent-to $\mathrm{T}$ lymphocytes and smooth muscle cells. ${ }^{1819}$ At the same time, areas rich in smooth muscle cells gradually declined from chronic stable angina to the most severe form of unstable angina. The inverse relation between the mean values for macrophage/ smooth muscle cell ratios from stable to unstable states, as demonstrated in our study, is important in this context, because it may affect plaque morphology. Dense accumulations of macrophages, activated by cytokines, may elaborate proteolytic enzymes which cause the breakdown of the fibrous cap collagen meshwork-a sequence considered to induce plaque instability. ${ }^{122021}$ On the other hand, the synthetic activity of smooth muscle cells may induce the production of extracellular matrix components and fibrillar collagens in particular, which are regarded as a prerequisite for plaque stability.

It appears that our observations could give rise to conflicting interpretations. On the one hand, the findings add further support to the idea that active inflammation in atherosclerotic plaques is involved in the onset of acute coronary syndromes, as previously reported. ${ }^{89}$ At the same time, however, similar inflamma- tory processes are present in culprit lesions of patients with chronic stable angina.

\section{HOW SHOULD CHRONIC INFLAMMATION IN} STABLE ANGINA BE INTERPRETED?

One could argue that macrophages merely reflect a constitutive phenomenon in atherosclerotic plaques, as suggested by Moreno et $a l^{8}$ and have limited, if any, relevance to plaque destabilisation. Other factors, such as tissue stress relations, could play a prime role. Loree $e t a l^{7}$ tested the effects of plaque geometry on circumferential stress fields. They found that a reduction in the fibrous cap thickness increased the peak circumferential stress in the plaque, whereas increasing the severity of stenosis actually decreased peak stress in the plaque. Richardson et $a l^{3}$ showed that regions with high circumferential stress correlate with sites of rupture. However, they also demonstrated that the site of rupture was influenced by variations in the mechanical strength of the fibrous cap tissues, due to focal accumulations of lipid-laden macrophages. They suggested that these lipid-laden macrophages may induce weak foci in the fibrous cap. This observation introduces a potential role for lipid-related inflammation. Our analysis of coronary atherosclerotic plaques with plaque rupture and thrombosis in patients who died of an acute transmural myocardial infarction, revealed that the immediate site of rupture was always characterised by the presence of an inflammatory infiltrate with the same features as seen in the plaques of patients with stable and unstable angina. ${ }^{10}$ One could argue, therefore, that destabilisation of the fibrous cap tissue sets the scene for high tensile stresses to cause caps to rupture. This line of thought is strengthened by the observation that macrophages isolated from atherosclerotic lesions are able to break down collagen. ${ }^{20}$ It appears, however, that proteolytic enzymes such as intracellular gelatinase B are also present in the atherosclerotic lesions of patients with clinically stable angina. ${ }^{22}$

At the same time, there are indications that the destabilising effects of chronic inflammation depend on the amount and nature of lipids within plaques-a known variable. Current research strongly suggests that lipids and especially oxidised low density lipoproteins initiate and/or sustain the smoldering inflammation in plaques. ${ }^{23}$ Recent lipid lowering trials have shown a minimal angiographic reduction in high grade coronary stenoses, but a consistent decrease in acute coronary events. ${ }^{24}{ }^{25}$ Libby $^{26}$ suggested that stabilisation of lesions might result from reducing the inflammatory stimuli provided by lipids. Our study provides data to endorse this view: none of the patients with chronic stable angina enrolled in this study had been treated with lipid lowering drugs, but all the culprit lesions contained inflammation.

About a fifth of culprit lesions in patients with chronic stable angina $(21 \cdot 4 \%)$ showed features of recent injury and repair. This observation is of considerable interest, because it could reflect a mitigation of the local tissue 
effect of the inflammatory process that could underlie a process of plaque erosion or rupture (without occlusive thrombus) and cause rapid plaque growth. ${ }^{27}$ This sequence could be the mechanism that underlies rapid progression of coronary artery disease in patients with chronic stable angina and may eventually induce clinically unstable angina in these patients. ${ }^{13}$ The inverse relation between inflammatory activity in plaque tissues and the clinical stability of ischaemic syndromes as presented in the study, supports a concept that reduction of inflammation leads to plaque stabilisation. Therefore, the functional status of lipid related inflammation in atherosclerotic plaques needs further elucidation. At the same time, however, we have to conclude that not all patients with chronic stable angina have histologically stable plaques in their culprit lesion.

1 Fuster V, Badimon L, Badimon J, Chesebro JH. Mechanisms of disease. I. The pathogenesis of coronary artery disease and the acute coronary syndromes. $N$ Engl $f$ Med 1992;326:242-50.

2 Davies MJ, Thomas AC. Plaque fissuring: the cause of acute myocardial infarction, sudden ischaemic death, and crescendo angina. Br Heart $¥$ 1985;53:363-73.

3 Richardson PD, Davies MJ, Born GVR. Influence of plaque configuration and stress distribution on fissuring plaque configuration and stress distribution on fissuring
of coronary atherosclerotic plaques. Lancet 1989;2: of coron

4 Falk E. Why do plaques rupture? Circulation 1992;86:III$30-42$.

5 Davies MJ, Richardson PD, Woolf N, Katz DR, Mann J. Risk of thrombosis in human atherosclerotic plaques: role of extracellular lipid, macrophage, and smooth muscle cell content. Br Heart $\mathcal{1}$ 1993;69:377-81.

6 Cheng GC, Loree HM, Kamm RD, Fishbein MC, Lee RT. Distribution of circumferential stress in ruptured and stable atherosclerotic lesions. Circulation 1993;87: 1179-87.

7 Loree HM, Kamm RD, Stringfellow RG, Lee RT. Effects of fibrous cap thickness on peak circumferential stress in model atherosclerotic vessels. Circ Res 1992;71:850-8.

8 Moreno PR, Falk E, Palacios IF, Newell JB, Fuster V, Fallon JT. Macrophage infiltration in acute coronary synFallon JT. Macrophage infiltration in acute coronary syndromes. Implicati

9 Arbustini E, De Servi S, Bramucci E, Porcu E, Constante $\mathrm{AM}$, Grasso $\mathrm{M}$, et al. Comparison of coronary lesions obtained by directional atherectomy in unstable angina, stable angina and restenosis after either atherectomy or angioplasty. Am $\mathcal{F}$ Cardiol 1995;75:675-82.
10 Van der Wal AC, Becker AE, van der Loos CM, Das PK Site of intimal rupture or erosion of thrombosed coronary atherosclerotic plaques is characterized by an inflammatory process irrespective of the dominant plaque morphology. Circulation 1994;89:36-44.

11 Alexander RW. Inflammation and coronary artery disease. N Engl F Med 1994;331:468-9.

12 Galis ZS, Sukhova GK, Lark MW, Libby P. Increased expression of matrix metalloproteinases and matrix expression of matrix metalloproteinases and matrix degrading activity in vulnerable regions of human

13 Kaski JC, Chester MR, Chen L, Katritsis D. Rapid angiographic progression of coronary artery disease in patients with angina pectoris. The role of complex stenosis morphology. Circulation 1995;92:2058-65.

14 Hangartner JRW, Charleston AJ, Davies MJ, Thomas AC. Morphological characteristics of clinically significan coronary artery stenosis in stable angina. $\mathrm{Br}$ Heart 1986;56:501-8.

15 Campeau L. Grading of angina pectoris. Circulation 1976; 54:522-3.

16 Braunwald E. Unstable angina: a classification. Circulation 1989;80:410-4.

17 Van der Loos CM, Das PK, van den Oord JJ, Houthof $H-J$ Multiple immunoenzyme staining techniques. Use of fluMultiple immunoenzyme staining techniques. Use of flubodies. F Immunol Methods 1989;117:45-52.

18 Hansson GK, Jonasson L, Seifert P, Stemme S. Immune mechanisms in atherosclerosis. Arteriosclerosis 1989;9: $567-78$

19 Van der Wal AC, Das PK, Bentz-van den Berg D, van de Loos CM, Becker AE. Atherosclerotic lesions in humans. In situ immunophenotypic analysis suggesting an

20 Galis Z, Sukhova response. Lab Invest 1989, S, Libby P. Macrophage foam cells from experimental atheroma constitutively produce matrix degrading proteinases. Proc Natl Acad Sci USA 1995;92:402-6.

21 Henney AM, Wakeley PR, Davies MJ, Foster K, Hembry $\mathrm{T}$, Murphy $\mathrm{G}$, et al. Localization of stromelysin gene expression in atherosclerotic plaques by in situ hybridizaexpression in atherosclerotic plaques by in situ hy

22 Brown DL, Hibbs MS, Kearney M, Loushin C, Isner JM. Identification of $92 \mathrm{kD}$ gelatinase in human coronar atherosclerotic lesions. Circulation 1995;91:2125-31.

23 Stemme S, Faber B, Holm J, Wiklund O, Witzum JL Hansson GK. T lymphocytes from human atherosclerotic plaques recognize oxidized low density lipoprotein Proc Natl Acad Sci USA 1995;92:3893-7.

24 Brown BG, Zhao X-Q, Sacco DE, Albers JJ. Lipid lowering and plaque regression: new insights into prevention of plaque disruption and clinical events in coronary disease. Circulation 1993;87:1781-91.

25 Jukema JW, Bruschke AVG, van Boven AJ, et al. Effects of lipid lowering by pravastatin on progression and regression of coronary artery disease in symptomatic men with normal to moderately elevated serum cholesterol levels: the Regression Growth Evaluation Statin Study the Regression Growth Evaluation

26 Libby P. Molecular basis of the acute coronary syndromes. Circulation 1995;91:2844-50.

27 Davies MJ, Bland JM, Hangartner JRW, Angelini A Thomas AC. Factors influencing the presence or absence of acute coronary artery thrombi in sudden ischaemic death. Eur Heart $₹$ 1989;10:203-8. 